\title{
The Optophone: An Instrument for Reading by Ear.
}

\author{
By Dr. E. E. Fournier D'Albe.
}

$\mathrm{T}^{\mathrm{H}}$ E type-reading optophone, an instrument designed to enable blind people to read ordinary print, was described in NATURE in 1914 (vol. xciv.; p. 4). At the British Scientific Products Exhibition of 1918 some public reading demonstrations were given with a somewhat improved apparatus exhibited by the writer and by $\mathrm{Mr}$. W. Forster Brown (see Nature, vol. cii., p. Io, September 5, I918). These demonstrations sufficed to show that all the essential problems of type-reading had been solved, but the instrument then exhibited had certain defects which militated against its prolonged and convenient use by blind persons. Thus, the displacement along the line of type was effected by turning a handle, which no blind person would care to use by the hour. The construction of the apparatus generally was not sufficiently solid and substantial, in view of the fact that it had to be put into the hands of a necessarily somewhat clumsy operator.

After the close of the exhibition the construction of the instrument was undertaken by Messrs. Barr and Stroud, Ltd., of Glasgow, the wellknown makers of range-finders and fire-control apparatus for the British and foreign navies. A great deal of thought and care has been bestowed upon the instrument by $\mathrm{Br}$. Archibald Barr, and the result has been a thoroughly sound, compact, and practical instrument, such as was shown by Dr. Barr in his lecture to the Royal Philosophical Society of Glasgow on March 24 last.

The general principle of the apparatus is shown by Fig. I. A siren $\operatorname{disc}, \mathrm{D}$, is run at about 30 revolutions a second by means of the small magneto-electric motor shown. It contains five circles of square perforations, the innermost circle having twenty-four perforations, the outermost forty-two, the other circles being intermediate and corresponding to the relative frequencies of certain notes of the diatonic scale. A line of light in a radial direction is provided by the festoon lamp L, and the image of the filament of this lamp is thrown upon the print by a system of three lenses on the other side of the selenium tablet S. The axis of the concavo-convex lens C is slightly tilted out of the axis of the other lenses for a purpose which is specified below. The general result of the optical system is to give a line of luminous dots on the print, each dot having a different musical frequency. The light constituting these dots is diffusely reflected back on to the selenium, which is put in circuit with a battery and a high-resistance telephone receiver. Those dots which fall on white paper produce a note of their own musical frequency in the telephone, while those which fall on black are extinguished. We thus get what may be called a "white-sounding" optophone, in which the black letters are read by the notes omitted from he NO. 2636 , VOL. IO5] scale rather than by the notes which remain sounding. All the reading demonstrations hitherto undertaken have been given with a "white-sounding " optophone.

A modification of this principle, introduced by Messrs. Barr and Stroud in consultation with the writer, is the provision of a second selenium preparation in the form of a cylindrical rod, the top of which can be seen at B (Fig. I). This rod receives the light reflected by the concave surface of the lens $\mathrm{C}$, which produces a real image of the line of dots on a generator of the cylindrical rod, and by turning this rod about its axis the image can be made more or less effective as desired. By balancing the effect on B against the effect on $\mathrm{S}$, when white paper alone is exposed, a silence can be produced in the telephone, and the effect of the passage of a black letter is to make a sound which varies in accordance with the formation of the letter. This is the principle of what may be called a "black-sounding" optophone, and

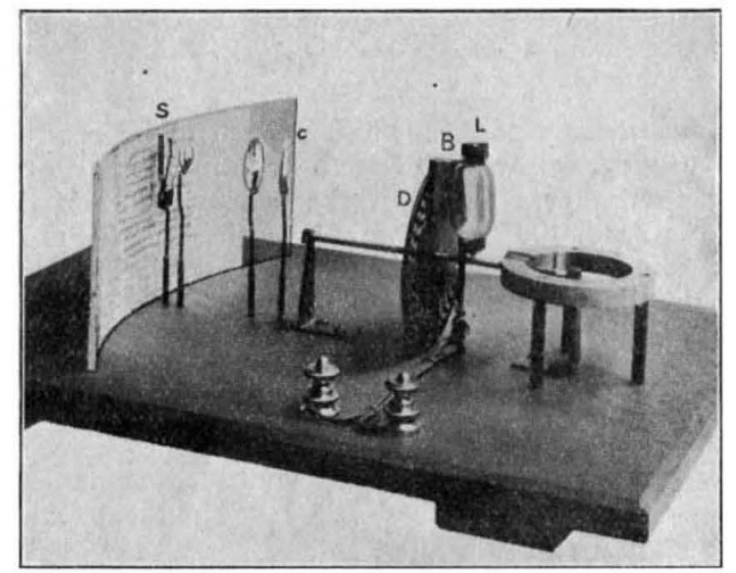

Fic. r. -Skeleton apparatus showing the principle of the optophone.

although its advantage over the white-sounding type has yet to be proved, there is little doubt that the learning of the alphabet sounded on the new principle will be easier, though in the writer's opinion the ultimate speed acquired by either blacksounding or white-sounding will be approximately the same. It is interesting in this connection to note that Miss Mary Jameson, the blind girl who gave the demonstrations at the rgr8 Exhibition, now reads habitually at a speed of about twentyfive words a minute with a "white-sounding" optophone made by Messrs. Barr and Stroud, and finds, indeed, that when the instrument is adjusted for a lesser speed reading becomes more difficult.

The present construction adopted by Messrs. Barr and Stroud is shown in Fig. 2. The disc, lamp, lenses, and selenium, as well as the motor, are all mounted in the swinging "tracer," which 
can be brought over to the right by means of the reading-handle $H$. It then returns to the left with a slow, silent, and steady motion regulated by the worm gearing $\mathrm{W}$, which drives a small paddle inserted in a viscous liquid. This paddle can be inserted more or less deeply into the liquid by the regulating nut $R$, and such is the range

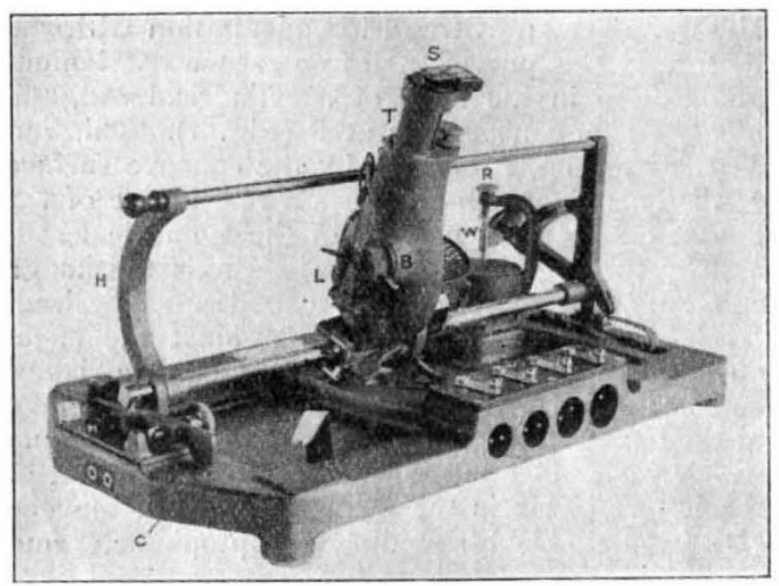

Fig. 2.-The optophone with book-rest removed.

of adjustment possible that a line can be read in anything from five seconds to five minutes, according to the proficiency of the reader. When the line is read, the next line is brought into focus by the change-bar $\mathrm{C}$, which works a friction grip inside the bar on which the "tracer" is pivoted, and can be adjusted for any desired line space

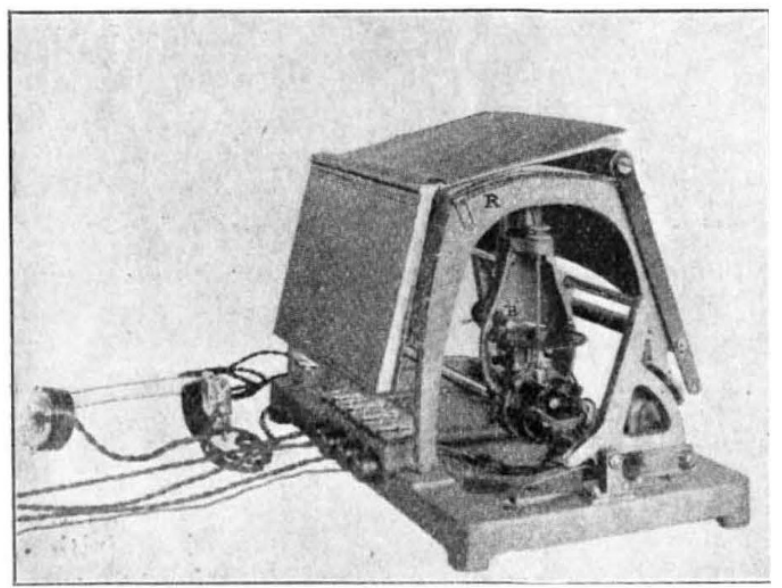

F1G. 3.-The optophone complete with book-rest.

by means of the screw attached to the change-bar. A lever attached to the "tracer" enables the operator to reverse this motion or to release the whole "tracer" from the friction gear, so that it may be quickly brought to the top of a page.

NO. 2636 , VOL. IO5]
The festoon lamp is inserted at $\mathrm{L}$, where it is held by a spring clip, and whence it can easily be removed for renewal even by a blind operator. The balancer is inserted at B, and can be adjusted for silence by means of the small handle shown.

Fig. 3 shows the apparatus from the top page end and with telephone and flex connections attached, as well as the book-rest $\mathbf{R}$ holding a book. The adapters of these flex connections are all of different sizes, and fit into different-sized holes in such a manner that they cannot be wrongly inserted-an important consideration with blind operators.

The various connections with their switches are for the motor, the lamp, and the two selenium circuits respectively. When the adapters are removed, a cover can be placed over the whole instrument, which clips on to the aluminium base, and the optophone can thereupon be carried about like a typewriter.

Fig. 4 shows the manner in which the instrument is manipulated by a blind person.

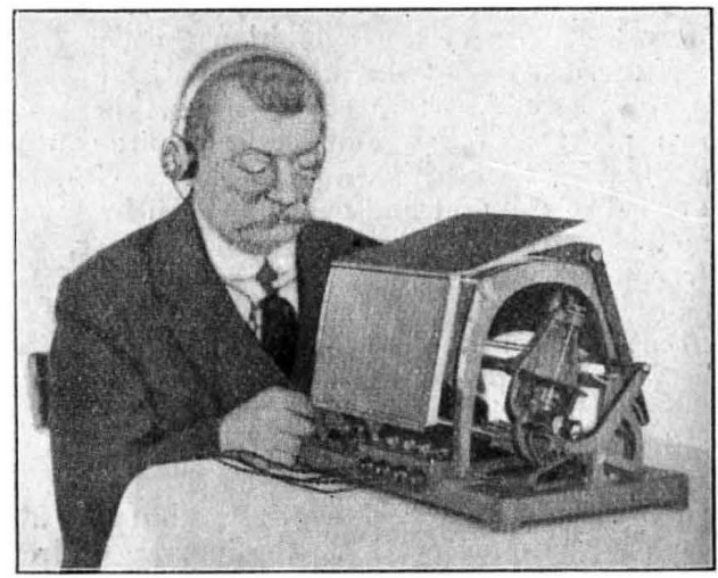

FIG. 4-- Line-changing with the optophone.

Special mention ought to be made of a contrivance for adjusting for various sizes of type. The middle lens of the three shown in Fig. I is mounted in a nut which can be screwed up and down within the "tracer" by means of two gaps cut in the upper cylindrical portion at T (Fig. 2). The nut is provided with six nicks across the rim, which enable a blind operator to count the number of turns of the nut, and thus to adjust for any definite size of type. This ingenious contrivance is, I believe, due to Dr. Stroud.

In practice it is found that, with the new apparatus, the various adjustments for size of type, length of line, and line interval are quite easily made by blind persons, and that the instrument, with all its delicate adjustments, can remain in use for a long time without anything getting out of order. It is therefore safe to say that the problem of opening the world's literature to the blind is now definitely solved. 